\section{A computer program for ordering-theoretic data analysis}

WILLIAM M. BART and KAUSTUBH LELE

University of Minnesota, Minneapolis, Minnesota 55455

and

RICHARD F. ANTONAK

Department of Education, University of New Hampshire, Durham, New Hampshire 03824

Ordering theory, a measurement model which extends scalogram analysis to include nonlinear item or task hierarchies in unidimensional as well as multidimensional configurations, allows for both the determination of an item or task hierarchy and the testing of a hypothesized hierarchy among a set of items or tasks. The prerequisite relation employed to generate the hierarchy is derived from formal logic: Item $i$ is prerequisite to item $j$ if and only if the response pattern $(0,1)$, where 0 represents a failure on item $i$ and 1 represents a success on item $\mathrm{j}$, occurs infrequently. That is, the response pattern $(0,1)$ is disconfirmatory of the hierarchical relation, item $i$ is prerequisite to item $j$.

To overcome the deterministic limitation shared with scalogram analysis concerning an inability of the model to consider random error occurrences in the item or task response data, ordering-theoretic analysis incorporates preset tolerance levels to establish the number of disconfirmatory response patterns that will be accepted in defining a prerequisite relation between two items. A prerequisite relation, whether hypothesized a priori or generated by the analysis, is accepted only if the frequency of disconfirmatory response patterns is less than or equal to the frequency of such response patterns established by the tolerance level.

Detailed discussions of ordering-theoretic data analysis have been provided elsewhere. Airasian and Bart (1973, Note 1) articulated the general nature of ordering theory. Bart and Krus (1973) described an orderingtheoretic technique by which item or task hierarchies could be determined. Krus and Bart (1974) discussed an application of the technique to multidimensional item scaling. Moreover, the technique has been applied to diverse data, including Piagetian task responses (Bart \& Airasian, 1974), propositional logic game item responses (Airasian, Bart, \& Greaney, 1975), and various attitudinal data (Bart, 1972a, b).

The program discussed in this paper searches out all of the prerequisite relations between all item pairs as described above, employing a user preset tolerance level(s) for each testing.

Input. The job deck consists of the following cards: title cards, a problem parameters card, tolerance level card(s), output options card, a data format card, a scoring key if the data is not in bivalued form (that is, 1 representing success and 0 representing failure), the data deck, and a last card. The first four cards describe the problem in a text which is reproduced on the output. The problem parameters card indicates the number of items, the number of subjects, whether the data are to be input in bivalued form or will need to be scored after input, and the number of tolerance levels to be considered for hierarchy construction. The tolerance level cards follow, with one level punched per card to the number specified on the problem parameters card. The output options card indicates user preference for printed output. The data format card is an I-type variable format card which indicates the location of the correct item responses on the following scoring key and of the raw scores (or bivalued data) on the subsequent data cards. Each of the data cards must contain the data for one subject; however, the use of more than one card per subject is permitted. If the user wishes to terminate the program, the last card must have the word END punched in columns 1-3. On the other hand, if the user wishes to analyze another set of data, the last card is a blank card and the job deck is arranged sequentially (as described above), beginning with the title cards.

Output.. The printed output includes (a) the titling information, (b) a summary of information on the problem parameters and tolerance level(s) cards, and (c) a summary of the computed item hierarchies for implication relations in the form $P$ is a prerequisite to $Q 1, Q 2, Q 3, \ldots$, etc. using each specified tolerance level. The user has the option of requesting (a) a matrix of scored item responses for each subject, (b) a response pattern matrix containing the number of $(1,1)$ and $(0,0)$ responses to all item pairs $(i, j),(c)$ a disconfirmatory response pattern matrix containing the number of $(0,1)$ responses to all items pairs $(i, j),(d)$ a disconfirmatory response pattern percentage matrix, (e) a table of percentages of confirmatory responses for relations of the type $P$ implies $Q$, and (f) a table of percentages of confirmatory responses for relations of the types not $P$ implies $Q$ and $P$ implies not $Q$.

Computer and Language. The program is written in FORTRAN-10 for processing by computers in the DEC -10 series and adaptable to CDC or IBM systems. Well documented, it has variable names that are mnemonic and correspond to the verbiage used by Bart and Krus (1973) and by Bart and Airasian (1974) to facilitate modification by the user.

Restrictions. The program has the following restrictions: (a) There cannot be more than 500 subjects, (b) there cannot be more than 100 items, and (c) the maximum number of tolerance levels to be considered is nine.

Availability. Copies of this paper and a source listing, 
which includes test data and printed output for two sample problems described by Bart and Krus (1973) and by Krus and Bart (1974), may be obtained without charge by writing to Richard F. Antonak, Department of Education, University of New Hampshire, Durham, New Hampshire 03824.

\section{REFERENCE NOTE}

1. Airasian, P. W., \& Bart, W. M. Tree theory: A theory generative measurement model. Paper read at the annual meeting of the American Educational Research Association. New: York. February 1971.

\section{REFERENCES}

Airasian, P. W.. \& Bart, W. M. Ordering theory: A new and useful measurement model. Educational Technology, 1973, 13. 56-60.

Airasian, P. W., Bart, W. M., \& Greaney, B. J. The analysis of a propositional logic game by ordering theory. Child Study Joumal. 1975. 5, 13-24.

BART, W. M. A hierarchy among attitudes toward animals. Journal of Environmental Education, 1972, 3, 4-6. (a)

BART, W. M. A hierarchy among attitudes toward the environment. Journal of Environmental Education, 1972. 4. 10-14. (b)

Bart. W. M., \& Airasian, P. W. The determination of the ordering among seven Piagetian tasks by an orderingtheoretic method. Journal of Educational Psychology. 1974. 66, 277.284.

BART, W. M., \& KRUS, D. J. An ordering-theoretic method to determine hierarchies among items. Educational and Psychological Measurement, 1973, 33, 291-300.

KRUS, D. J.. \& BART. W. M. An ordering-theoretic method of multidimensional scaling of items. Educational and Psychological Measurement, 1974, 34, 525-535. 